\title{
Thermochemical and Pyrolytic Analyses of Musa spp. Residues from the Rainforest Belt of Nigeria
}

\author{
Ayokunle 0. Balogun $\oplus^{\circ},{ }^{a}$ Olumuyiwa A. Lasode, ${ }^{b}$ and Armando G. McDonald $\mathbb{C}^{c}$ \\ ${ }^{a}$ Department of Mechanical Engineering, College of Science and Engineering, Landmark University, P.M.B. 1001, Omuaran, \\ Kwara State, Nigeria \\ ${ }^{b}$ Department of Mechanical Engineering, Faculty of Engineering and Technology, University of Ilorin, P.M.B. 1515 Ilorin, Nigeria; \\ olubusay02@gmail.com (for correspondence) \\ cDepartment of Forest, Rangeland and Fire Science, University of Idaho, Moscow, Idaho 83844-1132, Moscow
}

Published online 00 Month 2018 in Wiley Online Library (wileyonlinelibrary.com). DOI 10.1002/ep.12869

Four different morphological plant parts of Musa spp. (banana and plantain) residues obtained from the rainforest belt of Nigeria were investigated. The study undertook Fourier transform infrared (FTIR) spectroscopy, X-ray diffraction (XRD), and physicochemical analysis. The total crystallinity (TCI) and lateral order (LOI) indices showed that the cellulose crystallinity for banana pseudo-stem (LOI-5.18; TCI$0.37)$ and banana rachis (LOI-4.25; TCI-O.44) were relatively bigher than for the banana (LOI-O.11; TCI-0.2O) and plantain (LOI-O.17; TCI-O.18) peels. The XRD analysis confirmed the presence of starch in the peels and cellulose I in the structural samples (rachis and the pseudo-stem). A further demonstration of the marked differences between the morphological parts of Musa spp was highlighted in the analysis of the FAMES extract as banana peels $\left(21 \mathrm{mg} \mathrm{g}^{-1}\right.$ of biomass) and plantain peels (20 $\mathrm{mg} \mathrm{g}^{-1}$ of biomass) had the highest quantity of palmitic acids whereas the eicosanoic, behnic, and lignoceric acids were absent in the peels. The relatively high ash content $(\leq 12.30 \mathrm{wt} \%)$ in the Musa spp. samples may necessitate a pretreatment process prior to deployment for bioenergy or chemical extraction purposes. Furthermore, kinetic studies, which involved differential Friedman's and integral Flynn-Wall-Ozawa techniques, and analytical pyrolysis of the residues were undertaken. The activation energy varied continuously with conversion; reaching a peak of $>290 \mathrm{~kJ} / \mathrm{mol}$. The analytical pyrolysis detected acids, sugar derivatives, and phenolic compounds in significant concentrations for all biomass samples. () 2018 American Institute of Chemical Engineers Environ Prog, 00: 000-000, 2018

Keywords: kinetics, pyrolysis, Musa spp. residues, Nigeria, cellulose crystallinity

\section{NTRODUCTION}

Musa species (banana and plantain) is a staple fruit that is widely cultivated across the Rainforest belt of Nigeria [1]. Musa spp. bears fruit only once in its lifetime. After harvesting, the fruits are consumed raw, cooked or further processed into preserved food products. It is important to note that in developing countries like Nigeria, agricultural

\footnotetext{
Additional Supporting Information may be found in the online version of this article.

(C) 2018 American Institute of Chemical Engineers
}

practices are fraught with low level of processing, high postharvest losses and short shelf life [2]. The implication is that large amount of residues are generated from the farm right through the value-addition-chain processes. These residues have limited domestic and agricultural applications; thus engendering a measure of disposal challenges.

In the recent past, global attention has shifted to biomass as a crucial alternative energy source because of its renewable potentials, sustainability prospects and ecological compatibility. Furthermore, biomass resources are abundantly available as residues from agricultural activities at a relatively inexpensive cost. For instance, an FAOSTAT data [3] showed that Africa was the largest producer of plantain and that Nigeria was among the top ten producers with an average annual production of 2.4 million tonnes in 2014. Based on the "waste factor" estimated by Amoo-Gottfried and Hall [4], a huge amount $(>2.5$ million tonnes) of agricultural residues is being generated annually from plantain production in the country. From the foregoing, Musa spp. residues are attractive sources of non-woody renewable resources. These residues may be exploited as renewable energy resources, chemical extraction feedstock, and/or biocomposite fibers/ fillers.

Musa spp. residues are lignocellulosic materials, which are intricate network of polymer fractions, low molecular weight compounds (often referred to as extractives) and some inorganic minerals. The polymeric components are primarily responsible for the structural integrity and rigidity of the cell walls in plants. These components, however, could serve as potential sources of valorization for Musa spp. residues. For instance, it has been shown in the pulping of banana pseudo-stems that polysaccharides and lignin fractions are promising sources of fiber [5]. Extracts derived from Musa spp. residues may also form the base material from which bioactive compounds can be isolated. These bioactive compounds are beneficial in nutraceutical applications [6].

Significantly, the polymeric fractions vary from one agricultural biomass resource to another. They may also vary with different morphological plant parts as well as geographical regions [7]; thus necessitating some form of characterization. Fourier transform infrared (FTIR) spectroscopy; a nondestructive technique, is an advanced analytical technique that is valuable for the characterization of lignocellulosic biomass. For instance, the FTIR spectroscopy is capable 
of detecting the structural properties and functional groups in the polymeric matrix of biomass. Aside qualitative analysis, FTIR spectroscopy also allows semiquantitative analysis. However, most spectroscopic studies on Musa spp. residues have been qualitative $[7,8]$. This study will undertake a quantitative analysis employing two notable techniques for cellulose crystallinity determination. They are lateral order (LOI) and total crystallinity indices (TCI). The syringyl to guaiacyl $(\mathrm{S} / \mathrm{G})$ ratio will also be evaluated so as to gain some insight into the lignin structure. Crystalline structure of materials can also be probed by XRD analysis and is used to determine the extent of starch and cellulose crystallinity in various applications [9-11].

Furthermore, in harnessing the energy potential of biomass resources, the resources are often subjected to varied thermo-chemical conversion processes. Thermogravimetric analysis (TGA) is a potent analytical tool that gives insight into the thermal decomposition mechanism of lignocellulosic materials and also provides valuable data for computing kinetic parameters $[12,13]$. Model-free isoconversional techniques which closely approximate multi-step reactions have gained wide acceptability in kinetic studies [12,14]. Other merits of these techniques include elimination of any reaction model assumption and its amenability to multiple TGA measurements. The integral Flynn-Wall-Ozawa (FWO) and differential Friedman methods are two notable techniques that will be used in this study so as to validate and corroborate the consistency of the kinetic results $[12,14]$. In the process of thermochemical conversion, volatiles with diverse organic species are released. The application of such volatiles are primarily dependent on their chemical composition; thus necessitating a foreknowledge of the chemical makeup of such organics [15]. The analytical pyrolysis gas chromatography-mass spectrometry (Py-GC/MS) is a viable technique that is useful in prospecting the composition of volatiles from different biomass resources as demonstrated by Gao et al. [15] and Balogun et al. [16].

To the best of the authors' knowledge limited research efforts have been directed at characterizing Musa spp. resources of Nigerian origin using advanced analytical instruments. Therefore, the aim of this study was to subject Musa spp. residues obtained from the Rainforest belt of Nigeria to spectroscopic and XRD analyses alongside physicochemical analysis and higher heating value (HHV) determination. The lipophilic extracts will also be isolated, derivatized using acidic hydrolysis and subjected to GC/MS analysis. Finally, the TGA and analytical pyrolysis of the Musa spp. residues will be undertaken.

\section{EXPERIMENTAL}

\section{Sample Procurement and Preparation}

The Musa spp. plants were harvested on a farm at Elizade University $\left(7^{\circ} 22^{\prime} \mathrm{N}, 5^{\circ} 07^{\prime} \mathrm{E}\right)$, Ilara-Mokin, Ondo, Nigeria in September 2015. After harvesting, the plants were separated into different morphological parts, namely: banana peel (BP), banana pseudo-stem (BPS), banana rachis (BR) and plantain peel (PP), and oven dried at $100^{\circ} \mathrm{C}$ for $16 \mathrm{~h}$ (Figure 1). The samples were subsequently ground in a Thomas Wiley Laboratory Mill Model 4, sieved into particle sizes of $0.5-1.0 \mathrm{~mm}$ and stored in Ziploc bags at room temperature prior to analyses.

\section{Physicochemical and Calorific Value Analyses}

The volatile matter $(\mathrm{VM})\left(950^{\circ} \mathrm{C}\right.$ for $\left.7 \mathrm{~min}\right)$ and ash $\left(600^{\circ} \mathrm{C}\right.$ for $\left.16 \mathrm{~h}\right)$ contents were determined according to ASTM E870-82 and ASTM D1102-84 methods, respectively. C and $\mathrm{N}$ contents were determined using a Costech ESC 4010 elemental analyzer. The Musa spp. samples were extracted

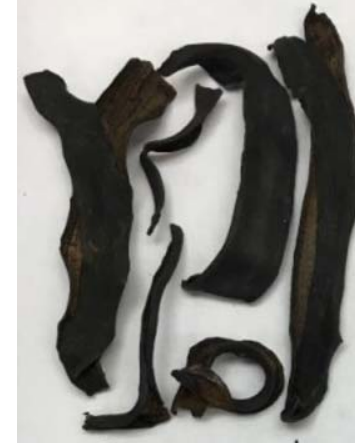

Banana peel

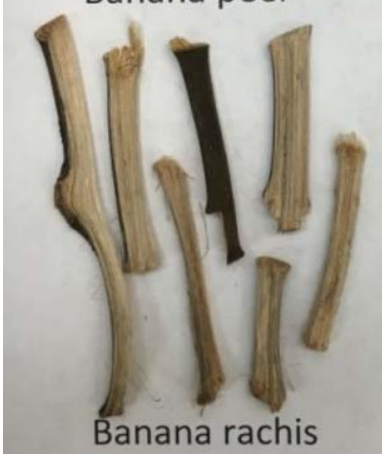

Banana rachis

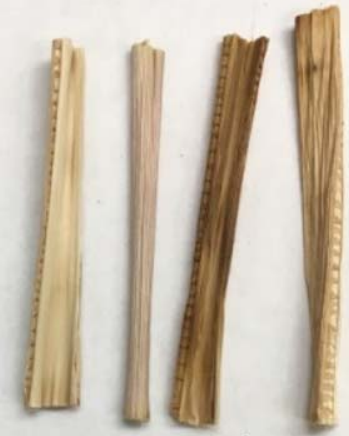

Banana pseudostem

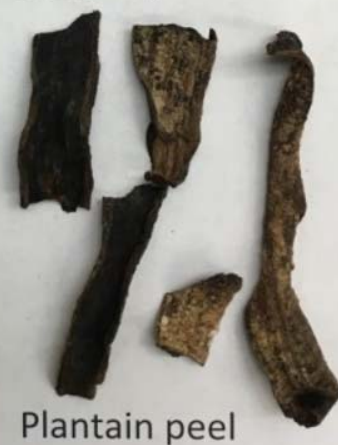

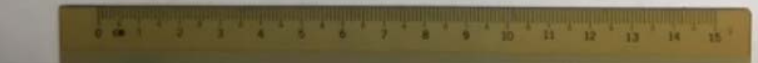

Figure 1. Photograph of dried banana peel (BP), banana pseudo-stem (BPS), banana rachis (BR), and plantain peel (PP). [Color figure can be viewed at wileyonlinelibrary. com]

using a Soxhlet apparatus with $\mathrm{CH}_{2} \mathrm{Cl}_{2}$ (HPLC/GC-MS grade, EMD Millipore) for $16 \mathrm{~h}$, the extract was concentrated to dryness, and the yield was determined gravimetrically according to ASTM D1108-96. This procedure only extracts lipophilic compounds at low temperature (about $40^{\circ} \mathrm{C}$ ) to minimize compound degradation. The lignin content was determined, in duplicate, according to the acetyl bromide procedure [17]. The carbohydrate analysis was determined, in duplicate, using a modified phenol-sulfuric acid method for cellulosic samples [18]. A Parr oxygen bomb calorimeter model 1341 (IL, USA) was used in the HHV determination (in duplicate).

\section{Spectroscopic and XRD Analyses}

FTIR spectra were acquired, in duplicate, using an Avatar 380 spectrometer (ThermoNicolet) in the single bounce attenuated total reflection (ATR) mode. Two spectra were gathered in the scan region of $400-4000 \mathrm{~cm}^{-1}$ with a resolution of $4 \mathrm{~cm}^{-1}$ and an accumulation of 64 scans. The cellulose TCI and LOI, and the lignin S/G ratio were determined as detailed in earlier publications $[19,20]$. Starch crystallinity was determined from the absorbance ratio of bands at 1047 and $1032 \mathrm{~cm}^{-1}$ [9]. The starch crystallinity index (SCI) and cellulose crystallinity index (CCI) were determined from the X-ray diffraction (XRD) (Rigaku MiniFlex 600 instrument, 5$50^{\circ}$ using $0.02^{\circ}$ steps) data. The diffractograms were peak fitted using IGOR Pro v6.3 software. SCI for starchy tissue (BP and $\mathrm{PP}$ ) was calculated from the summation of areas of crystalline peaks (peaks at $2 \theta=14.9,16.1,18.2,22.0 .24 .3,35.0$ ) divided by total peak area (crystalline + amorphous peaks) [10]. CCI for BPR and BS was determined from the ratio of the integral intensities, after peak fitting and amorphous baseline subtraction, of crystalline portions to the total 
Table 1. Physicochemical and calorific value analysis.

\begin{tabular}{|c|c|c|c|c|c|c|c|c|c|}
\hline \multirow[b]{2}{*}{ Biomass } & \multicolumn{3}{|c|}{$\begin{array}{c}\text { Proximate } \\
\text { analysis* (wt \%) }\end{array}$} & \multicolumn{2}{|c|}{$\begin{array}{c}\text { Elemental } \\
\text { analysis } \\
(w t \%)\end{array}$} & \multicolumn{3}{|c|}{$\begin{array}{c}\text { Compositional } \\
\left.\text { analysis** }^{* *} \text { wt } \%\right) \\
\end{array}$} & \multirow[b]{2}{*}{$\begin{array}{c}\text { HHV } \\
\left(\mathrm{MJ} \mathrm{kg}^{-1}\right)\end{array}$} \\
\hline & $\mathbf{V M}$ & FC & Ash & C & $\mathbf{N}$ & $\underset{\text { extractives }}{\mathrm{CH}_{2} \mathrm{Cl}_{2}}$ & Lignin & $\begin{array}{c}\text { Total } \\
\text { carbohydrate }\end{array}$ & \\
\hline $\mathrm{BP}$ & 68.02 & 19.68 & 12.30 & 43.38 & 2.06 & 10.9 & 28.3 & 48.9 & 19.28 \\
\hline BPS & 74.65 & 16.95 & 8.40 & 41.13 & 0.16 & 1.28 & 16.5 & 72.2 & 16.58 \\
\hline $\mathrm{BR}$ & 73.32 & 18.78 & 7.90 & 42.40 & 0.94 & 2.00 & 19.2 & 64.8 & 16.96 \\
\hline $\mathrm{PP}$ & 71.74 & 16.51 & 11.75 & 43.38 & 0.91 & 8.25 & 14.0 & 75.8 & 18.37 \\
\hline
\end{tabular}

*Dry basis.

***Dry-free-ash basis.

intensity of sample according to CCI $=\left[1-\left(I_{\mathrm{am}} / I_{\mathrm{O02}}\right)\right]$, where $I_{\mathrm{am}}$ is the intensity of the peak at $2 \theta=18^{\circ}$ and $I_{002}$ is the maximum intensity of the (002) plane diffraction at $2 \theta=22^{\circ}$ [11].

\section{GC/MS Analysis of Fatty Acid Methyl Esters (FAMEs) Derivatives}

The $\mathrm{CH}_{2} \mathrm{Cl}_{2}$ extracts $(5.0 \mathrm{mg}$ ) were derivatized (methanolysis using $2 \mathrm{~mL}$ of $\mathrm{MeOH} / \mathrm{H}_{2} \mathrm{SO}_{4} / \mathrm{CHCl}_{3}(1.7: 0.3: 2.0 \mathrm{v} / \mathrm{v} / \mathrm{v})$ at $90^{\circ} \mathrm{C}$ for $90 \mathrm{~min}$ ) into FAMEs according to a detailed procedure in a previous publication [21].

\section{Thermogravimetric Analysis and Analytical Pyrolysis (Py-GC/MS)}

TGA experiments (4-5 $\mathrm{mg}$, in duplicate, at four varied heating rates $5,10,20,30 \mathrm{~K} / \mathrm{min}$ ) were conducted on a Perkin Elmer TGA-7 instrument in a nitrogen purged environment. Data obtained from TGA were used in KAS and Friedman's method to determine the kinetic parameters. Analytical pyrolysis (Py-GC/MS at $500^{\circ} \mathrm{C}$ ) was carried out in a Projectors II (SGE Analytical Science) coupled to a GC-MS $S_{\mathrm{EI}}$ (FOCUS-ISQ, Thermoscientific) instrument using the same GC/MS parameters as above.

\section{Kinetic Modeling}

The global kinetic relation $[14,22]$ for biomass decomposition rate may be expressed as:

$\frac{\mathrm{d} \varnothing}{\mathrm{d} t}=k(T) f(\varnothing)$

where the temperature dependent function takes the form of Arrhenius expression:

$k(T)=A \exp ^{(-E / R T)}$

where $\varnothing$ is the degree of conversion, $T(K)$, is the temperature, $R$, is the universal gas constant $(8.314 \mathrm{~J} / \mathrm{mol} . \mathrm{K})$ and $E(\mathrm{~J} / \mathrm{mol})$, is the apparent activation energy. At constant heating rate, substituting Eq. (2) into Eq. (1) and integrating by separation of variables yields Eq. (3):

$\int_{0}^{\alpha} \frac{\mathrm{d} \alpha}{f(\alpha)}=g(\alpha)=\frac{A}{\beta} \int_{T_{0}}^{T} \exp \left(-\frac{E}{R T}\right) \mathrm{d} T$

Further mathematical manipulations yield Eq. (4), which contains a temperature integral that does not present a closedform solution [16].
$g(\alpha)=\left(\frac{\mathrm{AE}}{\beta R}\right)\left\{-\frac{\exp ^{x}}{x}+\int_{0}^{\infty}\left(\frac{\exp ^{x}}{x}\right) \mathrm{d} x\right\}=\left(\frac{\mathrm{AE}}{\beta R}\right) p(x)$

The approximation of the temperature integral, $p(x)$, according to Flynn Wall Ozawa; a notable integral method, is given by the relation in Eq. (5).

$\ln \beta=\ln \frac{\mathrm{AE}}{g(\alpha) R}-2.315-0.457 \frac{E}{\mathrm{RT}}$

where $\beta$ is the heating rate. The plot of $\ln (\beta)$ against the inverse of absolute temperature is expected to generate a straight line curve from the apparent activation energy can be evaluated. The pre-exponential factor can also be obtained from the intercept of the linear relation. On the other hand, Friedman's differential method is expressed as Eq. (6)

$\ln \frac{\mathrm{d} \varnothing}{\mathrm{d} t}=$ constant $-\frac{E}{\mathrm{RT}}$

Again the plot of $\ln \frac{\mathrm{d} \varnothing}{\mathrm{d} t}$ against $\frac{1}{T}$ should yield a straight line and the activation energy can be evaluated from the slope.

\section{RESULTS AND DISCUSSION}

\section{Physicochemical and Calorific Analyses}

The use of biomass residues for bioenergy applications and/or chemical extraction purposes is usually preceded by chemical analysis. This analysis gives important insight into the energy capabilities, physical, and chemical properties of the prospective feedstock. The physicochemical data and the HHV of the banana and plantain residues are presented in Table 1.

The VM content obtained for the residues investigated in this work is comparable to that of other agricultural residues: banana peel (87\%) [23], Sorghum bicolour glume (78.9\%), sugarcane bagasse (76.6\%), and almond shells (69.5\%) $[19,24]$. Due to the high VM content, the main step during thermochemical conversion process of these residues would be devolatilization, in which diverse organic species would be liberated. This may thus serve as a viable renewable source for either chemical extraction or bioenergy applications. The ash content for Musa spp. residues, particularly $\mathrm{BP}$ and PP, was significantly higher than most agricultural residues that have been studied $[25,26]$; with rice residues, been one of the few exceptions [24]. This trend has been reported in the literature [27]. It has been observed that inorganic elements in ash have undesirable impacts on chemicals 


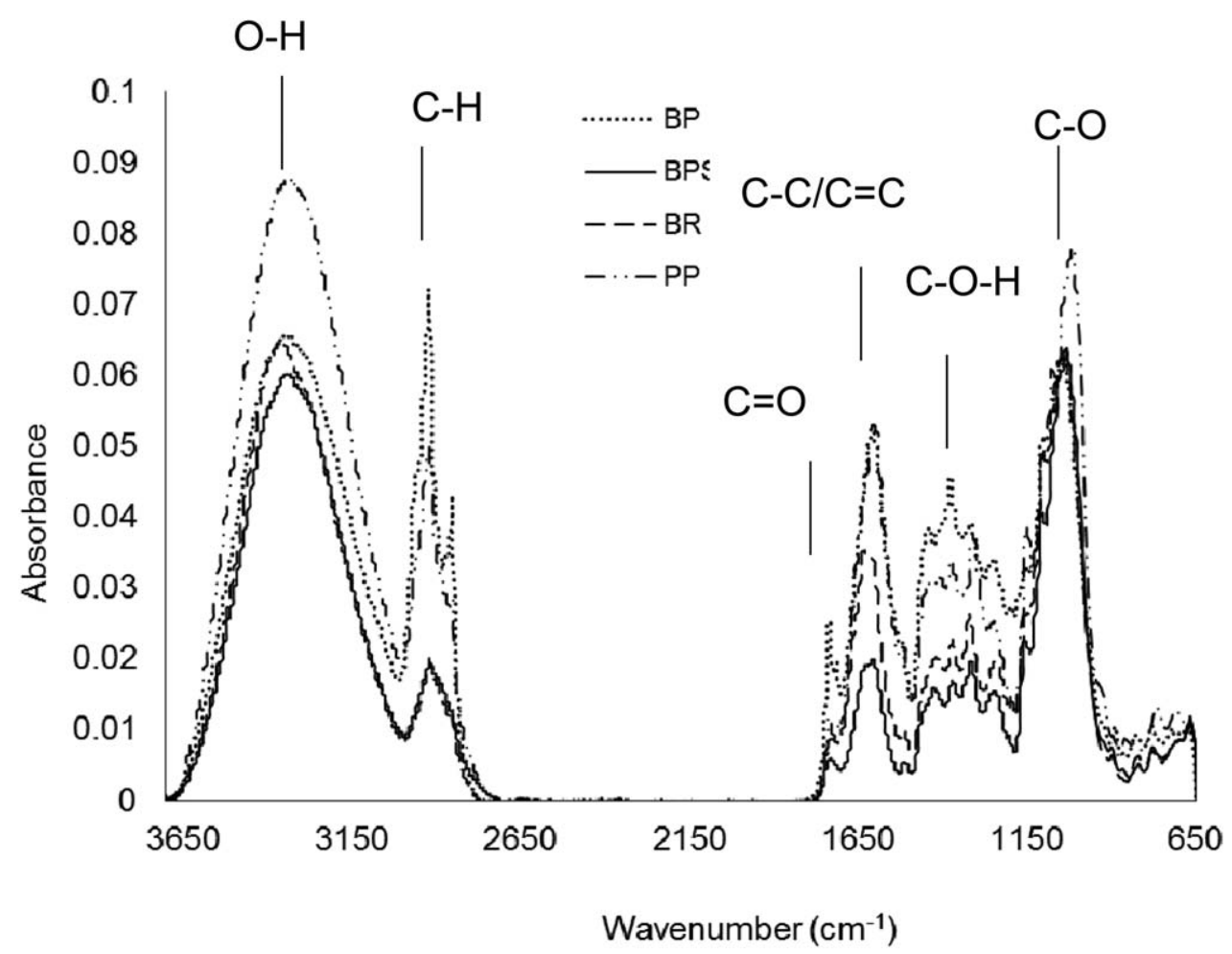

Figure 2. FTIR spectra of banana peel (BP), banana pseudo-stem (BPS), banana rachis (BR), and plantain peel (PP).

and energy recovery, Kraft pulping, and paper quality and yield [28-31]. This thus suggests that the application of Musa spp. residues for either chemical extraction or paper production may require some pretreatment processes so as to address the relatively high ash content in the residues. The $\mathrm{N}$ content for all the residues was $<1 \%$; with the only exception being BP. It may thus be argued that the deployment of Musa spp residues for thermochemical processes would yield low levels of oxides of nitrogen. In Table 1, BP and PP showed a much higher extractives content than BPS and BR. This discrepancy simply underscores the fact that the chemical composition profile of plants vary with tissue type [8]. The $\mathrm{CH}_{2} \mathrm{Cl}_{2}$ extractives content obtained in this study for BR and $\mathrm{BP}$ are comparable to the ones found in literature: banana rachis $(1.5 \%)$ and banana peel $(7.3 \% ; 6.9 \%)[6,7,32]$. Total carbohydrate contents were higher (49-76\%) than literature values (34-58\%) for Musa spp. plant material [7]. The discrepancy could be attributable to additional extraction steps (ethanol/toluene and water) employed by Oliveira et al. [7] which likely removed carbohydrate and thus gave lower values. The lignin content for Musa spp. residues (14$28 \%$ ) was generally in the range reported by Oliveira et al. at $11-24 \%$ [7]. It is noteworthy that $\mathrm{BP}$, with the highest $\mathrm{CH}_{2} \mathrm{Cl}_{2}$ extractives and lignin contents, has the highest HHV (19.28 $\mathrm{MJ} / \mathrm{kg}$ ). The HHV of biomass is largely influenced by variation in the extractives and lignin contents due to their higher C content [33].

\section{FTIR Spectroscopy of Banana and Plantain Residues}

The hemicellulose, cellulose, and lignin fractions are intricately intertwined in the cell wall of lignocellulosic resources and their compositions vary distinctly from biomass to biomass. FTIR spectroscopy is a powerful tool for the examination of the structural and chemical makeup of lignocellulosic biomass [12]. Figure 2 shows the FTIR spectra for Musa spp. residues. The spectra showed broad $\mathrm{OH}$ stretching band of hydroxyl group at about $3350 \mathrm{~cm}^{-1}$ and prominent bands of
Table 2. Lateral order index (LOI), total crystallinity index (TCI), starch crystallinity (SC) and syringyl to guaiacyl (S/G) ratio determined by FTIR spectroscopy and starch crystallinity index (SCI), and cellulose crystallinity index (CCI) determined by XRD for banana peel (BP), banana pseudo-stem (BPS), banana rachis (BR) and plantain peel (PP).

\begin{tabular}{lcccc}
\hline & BP & BPS & BR & PP \\
\hline LOI $\left(\mathrm{I}_{1429} / \mathrm{I}_{897}\right)$ & 0.11 & 5.18 & 4.25 & 0.17 \\
TCI $\left(\mathrm{I}_{1370} / \mathrm{I}_{2900}\right)$ & 0.20 & 0.37 & 0.44 & 0.18 \\
SC $\left(\mathrm{I}_{1047} / \mathrm{I}_{1032}\right)$ & 0.98 & & & 0.94 \\
CCI & 0.29 & 0.59 & 0.60 & \\
SCI & 0.7 & 0.8 & 1.1 & 0.21 \\
S/G ratio & & & & \\
\hline
\end{tabular}

C-H asymmetric stretching (2923 and $2855 \mathrm{~cm}^{-1}$ ) which originate from aliphatic structure of extractives and lignin $[19,34]$.

The characteristic absorption bands of cellulose identified were: $2900 \mathrm{~cm}^{-1}$ (C-H stretching), $1425 \mathrm{~cm}^{-1}(\mathrm{C}-\mathrm{H}$ wagging), $1370 \mathrm{~cm}^{-1}(\mathrm{C}-\mathrm{H}$ bending $)$ and $890 \mathrm{~cm}^{-1}\left(\mathrm{C}_{1}-\mathrm{O}-\mathrm{C}_{4}\right)$ $[19,33]$. The $\mathrm{C}-\mathrm{OH}$ and $\mathrm{O}-\mathrm{CH}_{3}$ stretching vibrations associated with the sharp absorption bands at about $1030 \mathrm{~cm}^{-1}$ are characteristic of lignin and cellulose constituents, while the intense band at about $1150 \mathrm{~cm}^{-1}$ are indicative of cellulose $\mathrm{C}-\mathrm{O}-\mathrm{C}$ bridges of amorphous cellulose [19]. Quantitatively, the degree of cellulose crystallinity can be evaluated from specific spectra bands in an FTIR spectrum. The LOI is deduced from the intensity ratios at about 1420 and $897 \mathrm{~cm}^{-1}$, while the TCI is deduced from 1370 and $2900 \mathrm{~cm}^{-1}$. Table 2 presents the LOI, TCI, and S/G for the lignocellulosic residues under investigation in this study.

The cellulose crystallinity in terms of LOI and TCI for BPS and BR were significantly higher than those for the peels (BP and PP) as well as other agricultural biomass in literature, Sorghum bicolour glume (0.75) [19]. From the foregoing, BP 
and PP may thus be expected to have relatively lower cellulose contents than BPS and BR. In addition, this may be an indication of subtle differences in the structural composition of Musa spp. tissue types. The LOI for BPS and BR falls within the range noted for chemical pulps (1.5-5.0) [35].

The aromatic stretching and ring vibrations, which are lignin characteristic bands, were displayed between the intensity peaks of 1430 and $1600 \mathrm{~cm}^{-1}$. Other lignin characteristic bands observed were about $1250 \mathrm{~cm}^{-1}(\mathrm{C}-\mathrm{O}$ of guaiacyl ring) and $1320 \mathrm{~cm}^{-1}(\mathrm{C}-\mathrm{O}$ of syringyl ring). The $\mathrm{S} / \mathrm{G}$ ratio for the residues ranges between 0.7 and 1.1 ; this value is comparable to 0.77 for banana floral stalk [36]; however, much lower than that of Sorghum bicolour glume (4.8) in an earlier publication [19].

The BP and PP were suspected to contain starch based on several bands (1152, 1100, 1075, 1047, 1032, 990, and $925 \mathrm{~cm}^{-1}$ ) associated with starch [37]. An indicator of starch crystallinity (SC) was determined from the ratio of absorbances at 1047 and $1032 \mathrm{~cm}^{-1}$ for BP (0.98) and PP (0.94) and values were comparable to literature (0.89-1.03) [9].

XRD analysis was performed to confirm the presence of starch and/or cellulose in the musa samples (Figure 3; Table 2). The BP and PP samples showed typical XRD patterns of starch; peaks showing at the $2 \theta$ scale at $14.9^{\circ}, 17.0^{\circ}, 22.1^{\circ}$, and $24.0^{\circ}$ were assigned to $\mathrm{A}$ and $\mathrm{B}$ type starches [10]. While the BR and BPS samples showed typical XRD patterns of cellulose I; peaks showing at $2 \theta$ scale at $15.6^{\circ}, 18.1^{\circ}$, and $21.8^{\circ}$ were assigned to the planes of $(101),(10-1)$, and (002), respectively [11]. CCI was determined for BR and BPS at 0.60 and 0.59 , respectively. Velasquez-Cock et al. [38] had isolated nanocellulose from banana pseudostems supporting its presence in BR and BPS samples.

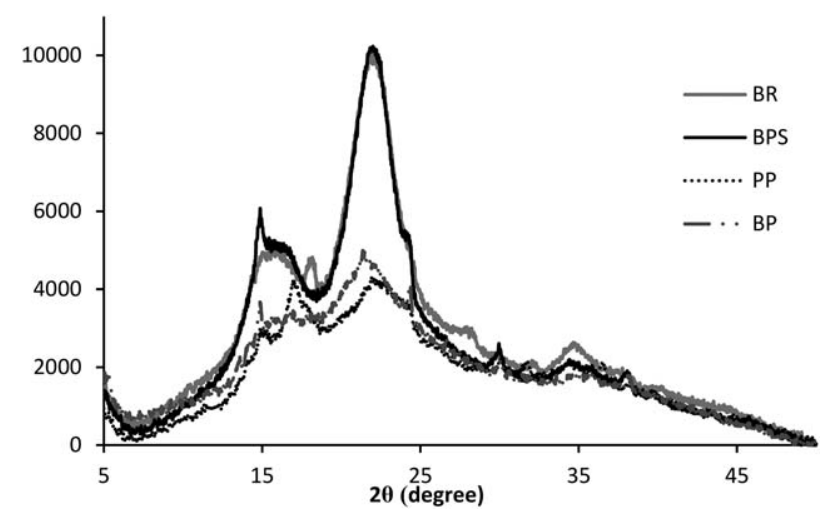

Figure 3. X-ray diffractograms of banana peel (BP), banana pseudo-stem (BPS), banana rachis (BR), and plantain peel (PP).

\section{Analysis of FAMEs Derivatives}

The identities and relative abundance of the compounds found in the derivatized $\mathrm{CH}_{2} \mathrm{Cl}_{2}$ extracts are shown in Table 3. A total of eight fatty acids were detected in the derivatized extracts of Musa spp. residues and five fatty acids were commonly found in all the extracts.

The most abundant fatty acid was palmitic acid followed by linoleic, oleic, stearic, and octadecenoic acids in descending order and consistent with the literature for banana extracts [6]. The highest quantity of palmitic acid was found in the peels extracts (PP; $20 \mathrm{mg} \mathrm{g}^{-1}$ of biomass, BP; $21 \mathrm{mg}$ $\mathrm{g}^{-1}$ of biomass), while linoleic ( $7 \mathrm{mg} \mathrm{g}^{-1}$ of biomass) and oleic ( $3 \mathrm{mg} \mathrm{g}^{-1}$ of biomass) acids were highest in BP. Eicosanoic, behnic, and lignoceric acids were absent in the peels (BP and PP). It has been suggested that there are some fatty and resin acids that could be used for biodiesel and biolubricant after transesterification [39,40]. Furthermore, the fatty acids identified in the $\mathrm{CH}_{2} \mathrm{Cl}_{2}$ extracts could be valuable phytochemicals, which would be useful in nutraceutical applications such as dermatology and the production of functional foods and cosmetics [6].

\section{Thermogravimetric Analysis}

Nonisothermal TGA experiments give useful information on the thermal decomposition mechanism of lignocellulosic biomass [13]. Figure 4 shows the TGA thermograms for BP, $\mathrm{BPS}, \mathrm{BR}$, and PP ran at $20 \mathrm{~K} / \mathrm{min}$ for comparative purposes. It is shown that the thermal decomposition profiles for all the agricultural residues are essentially similar. A small DTG peak was observed at a temperature below $423 \mathrm{~K}$ with an average of $4 \%$ mass loss on the TGA thermograms. This may be attributed to loss of moisture and/or low-molecular organic compounds. The major decomposition stage was

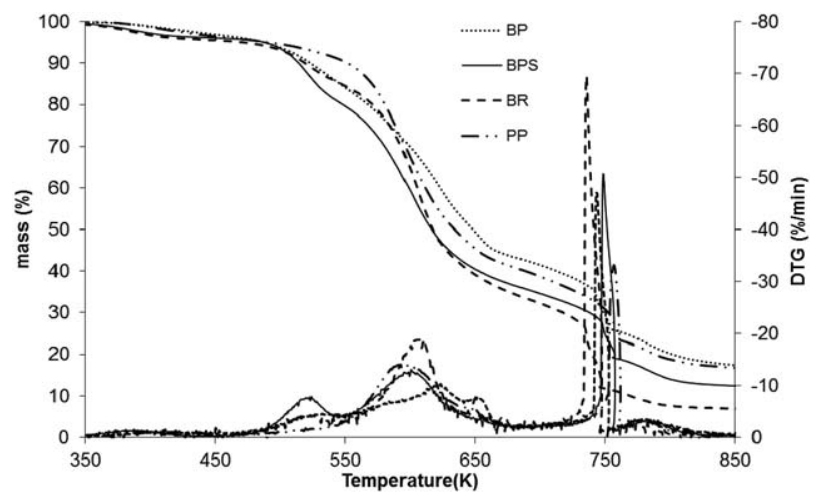

Figure 4. TGA thermograms at $20 \mathrm{~K} / \mathrm{min}$ for banana peel (BP), banana pseudo-stem (BPS), banana rachis (BR), and plantain peel (PP).

Table 3. Fatty acids identified and quantified as their FAME derivatives by GC/MS for banana peel (BP), banana pseudo-stem (BPS), banana rachis (BR), and plantain peel (PP) $\mathrm{CH}_{2} \mathrm{Cl}_{2}$ extracts.

\begin{tabular}{|c|c|c|c|c|c|c|}
\hline \multirow[b]{2}{*}{ Time (min) } & \multirow[b]{2}{*}{ COMPOUND } & \multirow[b]{2}{*}{$M^{+}(\mathbf{m} / \mathbf{z})$} & $\mathbf{B P}$ & BPS & BR & $\mathbf{P P}$ \\
\hline & & & \multicolumn{4}{|c|}{ (mg $\mathrm{g}^{-1}$ of biomass) } \\
\hline 31.85 & Palmitic acid & 270 & $20.90 \pm 0.63$ & $2.25 \pm 0.09$ & $2.82 \pm 0.07$ & $19.79 \pm 0.59$ \\
\hline 35.02 & Linoleic acid & 294 & $7.23 \pm 0.22$ & $1.12 \pm 0.03$ & $1.09 \pm 0.03$ & $3.15 \pm 0.10$ \\
\hline 35.14 & Oleic acid & 296 & $3.31 \pm 0.10$ & $1.08 \pm 0.03$ & $0.67 \pm 0.002$ & $3.21 \pm 0.10$ \\
\hline 35.21 & Octadecenoic acid (C18:1) & 296 & $0.41 \pm 0.12$ & $0.06 \pm 0.002$ & $0.09 \pm 0.01$ & $1.18 \pm 0.04$ \\
\hline 35.61 & Stearic acid & 298 & $1.39 \pm 0.04$ & $0.23 \pm 0.01$ & $0.21 \pm 0.01$ & $1.11 \pm 0.03$ \\
\hline 39.07 & Eicosanoic acid & 326 & 0.0 & $0.05 \pm 0.002$ & 0.0 & 0.0 \\
\hline 42.24 & Behnic acid & 354 & 0.0 & $0.07 \pm 0.002$ & $0.11 \pm 0.003$ & 0.0 \\
\hline 45.20 & Lignoceric acid & 382 & 0.0 & $0.04 \pm 0.001$ & $0.13 \pm 0.004$ & 0.0 \\
\hline
\end{tabular}


Table 4. Temperature profile characteristics of BP, BPS, BR, and PP.

\begin{tabular}{|c|c|c|c|c|c|c|c|c|c|c|c|c|c|c|c|c|}
\hline \multirow{3}{*}{$\begin{array}{l}\text { Heating } \\
\text { rate } \\
\left({ }^{\circ} \mathrm{C} / \mathrm{min}\right)\end{array}$} & \multicolumn{4}{|c|}{ BP } & \multicolumn{4}{|c|}{ BPS } & \multicolumn{4}{|c|}{ BR } & \multicolumn{4}{|c|}{ PP } \\
\hline & \multicolumn{3}{|c|}{ Temperature $\left({ }^{\circ} \mathrm{C}\right)$} & \multirow[b]{2}{*}{$\begin{array}{c}R_{\mathrm{W}} \\
(\%)\end{array}$} & \multicolumn{3}{|c|}{ Temperature $\left({ }^{\circ} \mathrm{C}\right)$} & \multirow[b]{2}{*}{$\begin{array}{c}R_{\mathrm{W}} \\
(\%)\end{array}$} & \multicolumn{3}{|c|}{ Temperature $\left({ }^{\circ} \mathrm{C}\right)$} & \multirow[b]{2}{*}{$\begin{array}{c}R_{\mathrm{W}} \\
(\%)\end{array}$} & \multicolumn{3}{|c|}{ Temperature $\left({ }^{\circ} \mathrm{C}\right)$} & \multirow[b]{2}{*}{$\begin{array}{c}R_{\mathrm{W}} \\
(\%)\end{array}$} \\
\hline & $T_{\mathrm{i}}$ & $T_{\mathrm{m}}$ & $T_{\mathrm{f}}$ & & $T_{\mathrm{i}}$ & $T_{\mathrm{m}}$ & $T_{\mathrm{f}}$ & & $T_{\mathrm{i}}$ & $T_{\mathrm{m}}$ & $T_{\mathrm{f}}$ & & $T_{\mathrm{i}}$ & $T_{\mathrm{m}}$ & $T_{\mathrm{f}}$ & \\
\hline 5 & 189.1 & 467.5 & 324.4 & 10.7 & 139.0 & 468.6 & 320.4 & & 82.7 & 485.8 & 313.0 & 6.9 & 145.1 & 487.3 & 299.9 & 9.7 \\
\hline 10 & 207.7 & 474.6 & 348.4 & 11.4 & 144.1 & 462.8 & 472.5 & 7.6 & 106.5 & 506.6 & 322.9 & 6.7 & 152.3 & 493.3 & 304.1 & 10.0 \\
\hline 20 & 210.3 & 486.0 & 460.1 & 11.6 & 165.3 & 477.4 & 475.3 & 8.1 & 112.7 & 517.4 & 462.6 & 5.8 & 156.9 & 503.8 & 470.9 & 11.5 \\
\hline 30 & 211.2 & 491.2 & 352.3 & 12.4 & 168.2 & 493.3 & 482.9 & 7.6 & 132.4 & 531.3 & 465.1 & 7.2 & 158.8 & 515.2 & 320.1 & 11.3 \\
\hline
\end{tabular}

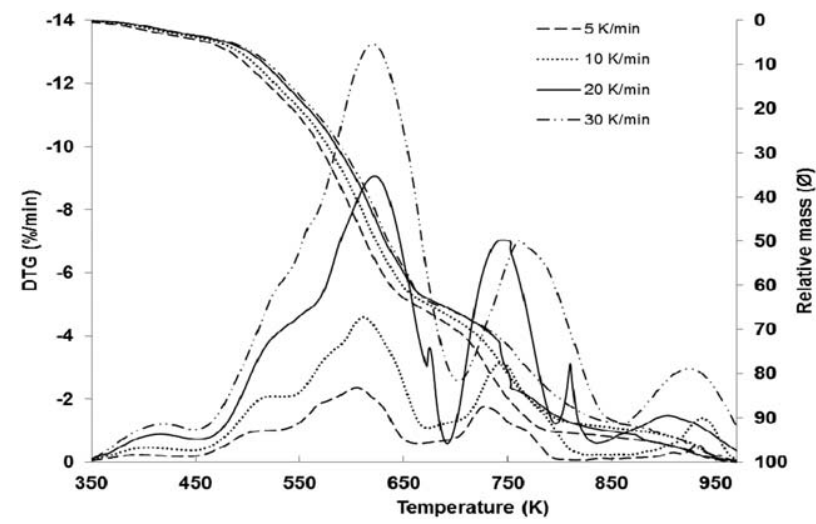

Figure 5. Typical plot showing the effect of heating rates on decomposition profile for BP.

observed between 473 and $723 \mathrm{~K}$ with an exponential decline in the curves. This stage primarily corresponds to the structural breakdown of the hemicellulose and cellulose fractions [14]. The former decomposes at a relatively lower temperature because of its higher reactivity. The cellulose fraction, on the other hand, is fairly stable at $\leq 523 \mathrm{~K}$ due to its relatively high degree of polymerization and ordered crystallinity; however, above this temperature it decomposes rapidly [20,41].

Subsequently, a gradual and fairly constant mass loss was observed above $473 \mathrm{~K}$. Although this has been traditionally assigned to lignin decomposition, it is important to mention that lignin being the most stable of the biomass polymeric fractions degrades over a wide range of temperature. However, the DTG peaks about $750 \mathrm{~K}$ may be an indication of a further thermal cracking of some resultant organic compounds, which may have been formed during the primary devolatilization reactions [16]. The TGA thermograms reveal that the residue left in descending order is as follows; $\mathrm{BP}>\mathrm{PP}>\mathrm{BPS}>\mathrm{BR}$, in other words, the residue left after the thermal degradation was highest for BP and lowest for BR. It is noteworthy that this trend corresponds to the ash content for the biomass samples as shown by the proximate analysis (Table 1). Table 4 presents the temperature profile characteristics for BP, BPS, BR, and PP. The variables are defined as follows: $T_{\mathrm{i}}, T_{\mathrm{O}}$, represents the onset, offset temperatures respectively, while $T_{\max }$, is the temperature at the maximum mass loss rate $\left(\mathrm{DTG}_{\max }\right)$. The $R_{\mathrm{W}}$ corresponds to the residual mass left after the thermal decomposition process in the TGA. But a few exceptions, it was observed that temperatures and the residual weights shifted to higher values with increasing heating rates. This is in agreement with findings in publications [16,42]. At higher heating rates, heat transfer limitations are experienced leading to the creation of a temperature gradient between the outer and the inner layers of the test sample. Thus a higher decomposition temperature
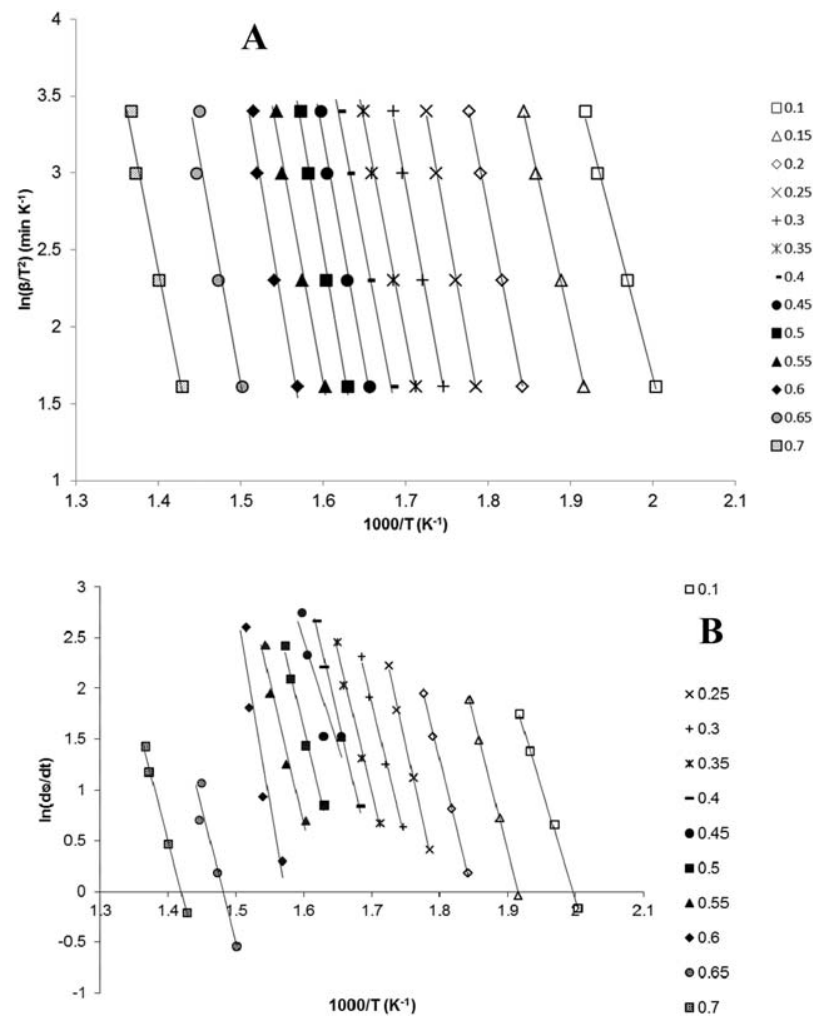

Figure 6. A typical isoconversional (0.1-0.7) lines graphs for $\mathrm{BP}$ used in the determination of $E$ according to (a) FWO and (b) Friedman's technique.

may be expected to set in. Furthermore, at low heating rates, exchange of heat is enhanced and this promotes mass diffusion and consequently higher mass is experienced.

\section{Kinetic Analysis}

The TGA measurements were normalized according to the mathematical relation in Eq. (7):

$\varnothing=\frac{m_{0}-m}{m_{0}-m_{\infty}}$

where $\varnothing$ is the conversion ratio, $m_{0}$ is the initial mass, $m_{\infty}$ is the final residual mass, and $m$ is the mass measured by the TGA. The thermal degradation profiles obtained for the biomass samples at different heating rates $(5,10,20,30 \mathrm{~K} /$ min) followed essentially the same trend. Therefore, BP was chosen as a typical plot for the study of biomass decomposition kinetics (Figure 5). The application of Eqs. (5) and (6) to the TGA data generated plots of isoconversional lines from which the activation energy was estimated at each 
Table 5. Activation energy $(E)$ and correlation coefficients for [Errorhx2205] of 0.1-0.7 for BP using KAS and Friedman's technique.

\begin{tabular}{|c|c|c|c|c|c|c|}
\hline \multirow[b]{2}{*}{ Conversion $(\varnothing)$} & \multicolumn{3}{|c|}{ FWO } & \multicolumn{2}{|c|}{ Friedman } & \multirow{2}{*}{$\begin{array}{l}\% \text { difference for } \\
\text { the values of } E_{\mathrm{s}}\end{array}$} \\
\hline & $E\left(\mathrm{~kJ} \mathrm{~mol}^{-1}\right)$ & $R^{2}$ & $\boldsymbol{A}$ & $\left.\overline{E(\mathrm{~kJ} \mathrm{~mol}}{ }^{-1}\right)$ & $R^{2}$ & \\
\hline 0.10 & 170.7 & 0.997 & $2.03 \times 10^{16}$ & 183.5 & 0.998 & 7.0 \\
\hline 0.15 & 203.3 & 0.999 & $2.63 \times 10^{16}$ & 220.1 & 0.999 & 7.6 \\
\hline 0.20 & 227.4 & 0.999 & $3.22 \times 10^{16}$ & 225.8 & 0.999 & -0.7 \\
\hline 0.25 & 245.6 & 0.999 & $3.85 \times 10^{16}$ & 247.0 & 0.998 & 0.6 \\
\hline 0.30 & 240.0 & 0.998 & $4.88 \times 10^{16}$ & 224.5 & 0.995 & -6.9 \\
\hline 0.35 & 230.3 & 0.996 & $6.14 \times 10^{16}$ & 229.1 & 0.991 & -0.5 \\
\hline 0.40 & 231.1 & 0.996 & $7.26 \times 10^{16}$ & 235.4 & 0.988 & 1.8 \\
\hline 0.45 & 246.2 & 0.989 & $7.98 \times 10^{16}$ & 172.2 & 0.805 & -42.9 \\
\hline 0.50 & 254.0 & 0.992 & $8.93 \times 10^{16}$ & 225.7 & 0.989 & -13.0 \\
\hline 0.55 & 242.6 & 0.986 & $1.08 \times 10^{17}$ & 232.4 & 0.961 & -4.4 \\
\hline 0.60 & 262.2 & 0.970 & $1.15 \times 10^{17}$ & 321.4 & 0.893 & 18.4 \\
\hline 0.65 & 245.9 & 0.916 & $1.40 \times 10^{17}$ & 218.4 & 0.920 & -12.6 \\
\hline 0.70 & 229.1 & 0.982 & $1.73 \times 10^{17}$ & 216.7 & 0.995 & -5.7 \\
\hline Average & 232.0 & & & 227.1 & & \\
\hline
\end{tabular}
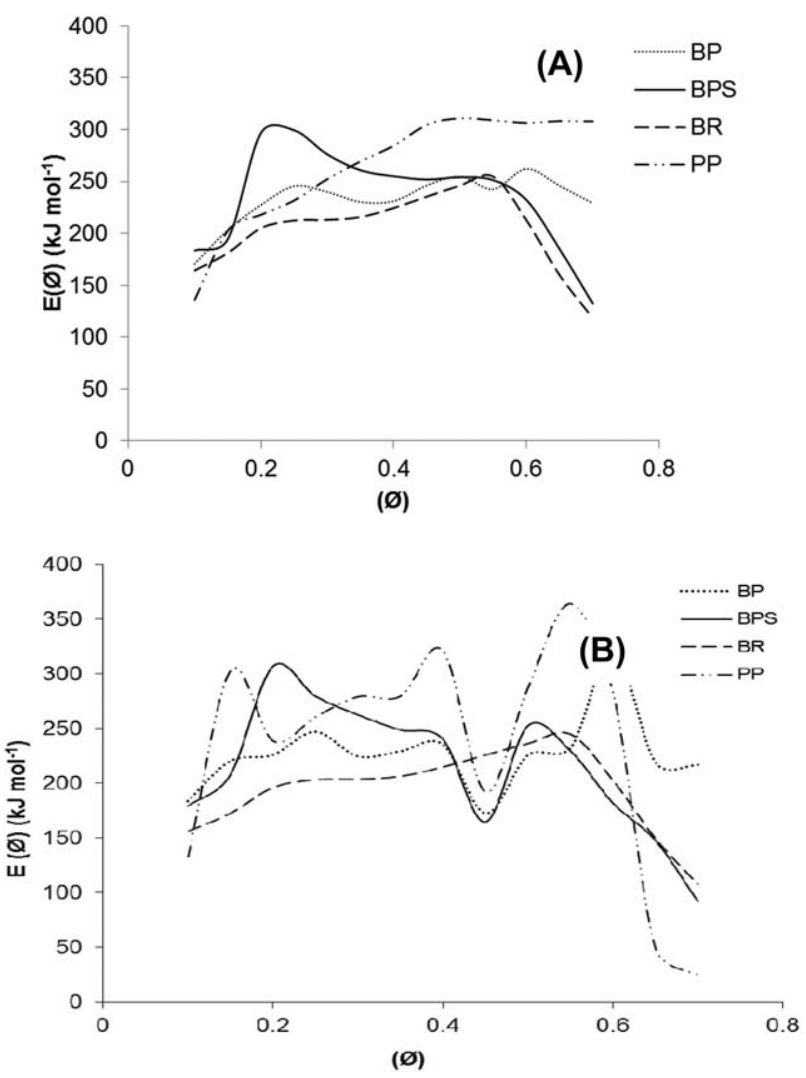

Figure 7. Activation energy, $E(\varnothing)$, as function of conversion ratio, $(\varnothing)$, obtained from (a) FWO and (b) Friedman's methods for banana peel (BP), banana pseudo-stem (BPS), banana rachis (BR), and plantain peel (PP).

conversion step. The plots for the four biomass residues under investigation showed similar trends. Hence, Figures 6A and $6 \mathrm{~B}$, respectively, are typical plots of $\ln (\beta)$ against $1 / T$ and $\ln (\mathrm{d} \varnothing / \mathrm{d} t)$ against $1 / T$ at progressive $\varnothing$ ratios $(0.1-0.7)$ and increasing $\beta(5,10,20,30 \mathrm{~K} / \mathrm{min})$ for BP. Table 5 shows the values obtained for $E$, their percentage difference in terms of FWO and Friedman's techniques, the correlation coefficients, and the pre-exponential factor A $(\varnothing$ ratios; $0.1-$ 0.7) for BP sample. The deduction of kinetic data was restricted to the above mentioned $\varnothing$ due to poor correlation outside this range. This may not be unconnected with the fact that the early stage of biomass degradation is more of a physical process (dehydration) and chemical kinetic models are inadequate to capture this process.

It was observed that the \% difference between the values of $E$ for both methods was as high as $42 \%$ at $0.45 \varnothing$ ratio. These findings were in contrast to a previous study [16]. The distinction (integral FWO and differential Friedman) between the techniques adopted might be a possible explanation for this occurrence. There was good correlation for the most part of the conversion process as indicated by high values of $R^{2}$; though those for FWO were relatively higher.

Figure 7 illustrates the variation between the $E(\varnothing)$ as a function of $\varnothing$ based on FWO and Friedman's technique between $\varnothing$ of $0.1-0.7$ for all biomass samples. It was observed that both techniques returned values of $E(\varnothing)$ that were fairly within the same range $(<100 E<290 \mathrm{~kJ} / \mathrm{mol})$. These values are in agreement with those obtained in literature for lignocellulosic biomass of agricultural origin [12,20]. Generally, the intricacy of activation energy dependence on the extent of conversion is lucidly demonstrated as $E(\varnothing)$ varies continuously with the progression of conversion. For instance, $E(\varnothing)$ for BPS in either technique, rises sharply from around $177 \mathrm{~kJ} / \mathrm{mol}$ (at $\varnothing$ ratio of 0.1 ) to $>270 \mathrm{~kJ} / \mathrm{mol}$ (at $\varnothing$ ratio of 0.25 ). The collective influence of the three polymeric fractions; though in different intensity, is not unlikely [43]. Subsequently, $E(\varnothing)$ deeps slightly, hovers around an approximate value of $>210 \mathrm{~kJ} / \mathrm{mol}$ and finally plunges to about $100 \mathrm{~kJ} / \mathrm{mol}$ (at $\varnothing$ ratio of 0.7 ). The heterogeneity of lignocellulosic biomass primarily accounts for this complex phenomenon. It is noteworthy that prior to the final plunge a characteristic peak usually emerges. This may be attributed to the energy barrier that must be surmounted in the last decomposition stage of the residual lignin [12]. More so, secondary reactions from reacting compounds and the creation of new bonds arising from crosslinking, polycondensation, and/or cyclization in char could also contribute to this trend [20]. It was observed that $\mathrm{BR}$ had the least average apparent activation energy, while PP had the highest for both techniques. Significantly, BR had higher values of LOI (4.25\%) and TCI (0.44\%) when compared with PP (LOI-0.17; TCI-0.18) as shown in Table 2. The decomposition kinetics of lignocellulosic materials, being a complicated phenomenon that follows a multiple and competitive pathways, can thus be better explained as multistep reaction mechanisms. 
Table 6. Analytical Py-GC/MS of BP, BPS, BR, and PP showing retention time, molecular ion, compounds and \% peak area.

\begin{tabular}{|c|c|c|c|c|c|c|}
\hline \multirow{2}{*}{$\begin{array}{l}\text { Retention } \\
\text { time (min) }\end{array}$} & \multirow[b]{2}{*}{ Compound } & \multirow[b]{2}{*}{$M^{+}$} & \multirow{2}{*}{$\frac{\mathrm{BP}}{\% \text { area peak }}$} & \multirow[t]{2}{*}{ BPS } & \multirow[t]{2}{*}{ BR } & \multirow[t]{2}{*}{$\mathbf{P P}$} \\
\hline & & & & & & \\
\hline 1.29 & Carbon dioxide & 44 & $17.40 \pm \pm 0.70$ & $22.20 \pm 0.90$ & $25.80 \pm 1.00$ & $12.40 \pm 0.50$ \\
\hline 1.52 & Furan & 68 & $7.40 \pm 0.30$ & $8.00 \pm 0.30$ & $7.30 \pm 0.30$ & $5.10 \pm 0.20$ \\
\hline 1.91 & Acetic acid & 60 & $6.10 \pm 0.20$ & $9.50 \pm 0.40$ & $9.00 \pm 0.40$ & $6.10 \pm 0.20$ \\
\hline 2.21 & 1-hydroxy-2-propanone & 74 & $3.10 \pm 0.10$ & $8.40 \pm 0.30$ & $6.10 \pm 0.20$ & $7.70 \pm 0.30$ \\
\hline 2.48 & Unknown & 100 & $0.40 \pm 0.02$ & $0.70 \pm 0.03$ & $0.60 \pm 0.02$ & $0.30 \pm 0.01$ \\
\hline 2.64 & 2,5 dimethyl furan & 96 & $1.10 \pm 0.04$ & $0.40 \pm 0.02$ & $0.30 \pm 0.01$ & $0.60 \pm 0.02$ \\
\hline 3.45 & $\mathrm{C}_{7} \mathrm{H}_{8}$ unknown & 92 & $1.30 \pm 0.04$ & $2.20 \pm 0.20$ & $2.00 \pm 0.10$ & $1.40 \pm 0.04$ \\
\hline 3.64 & Butanedial & 86 & $0.10 \pm 0.01$ & $1.80 \pm 0.10$ & $1.50 \pm 0.10$ & $1.00 \pm 0.04$ \\
\hline 3.76 & Methyl pyruvate & 102 & $1.00 \pm 0.04$ & $2.10 \pm 0.10$ & $1.50 \pm 0.10$ & $1.10 \pm 0.04$ \\
\hline 4.67 & Furfural & 96 & $1.00 \pm 0.04$ & $1.30 \pm 0.10$ & $1.00 \pm 0.04$ & $1.00 \pm 0.04$ \\
\hline 4.85 & 2-Furanmethanol & 98 & $0.50 \pm 0.02$ & $0.30 \pm 0.01$ & $0.10 \pm 0.01$ & $0.30 \pm 0.01$ \\
\hline 5.45 & 1 acetoxy-2-propanone & 116 & $1.00 \pm 0.04$ & $1.20 \pm 0.10$ & $1.00 \pm 0.04$ & $0.80 \pm 0.03$ \\
\hline 6.61 & $2(5 \mathrm{H})$-Furanone & 84 & $0.50 \pm 0.02$ & $1.10 \pm 0.05$ & $0.80 \pm 0.03$ & $1.00 \pm 0.04$ \\
\hline 6.93 & 1,2-Cyclopentanedione & 98 & $0.80 \pm 0.03$ & $2.10 \pm 0.10$ & $1.70 \pm 0.10$ & $2.10 \pm 0.10$ \\
\hline 8.57 & Phenol & 94 & $1.00 \pm 0.04$ & $0.50 \pm 0.02$ & $0.40 \pm 0.02$ & $0.80 \pm 0.03$ \\
\hline 9.80 & $\begin{array}{l}\text { 2-hydroxy-3-methyl-2-cyclopenten-1- } \\
\text { one }\end{array}$ & 112 & - & $1.60 \pm 0.10$ & $1.30 \pm 0.10$ & - \\
\hline 9.89 & Limonene & 136 & $3.70 \pm 0.10$ & - & - & $3.30 \pm 0.10$ \\
\hline 10.15 & 2,3 dimethyl-2-cyclopenten-1-one & 110 & $0.30 \pm 0.02$ & $0.30 \pm 0.02$ & $0.30 \pm 0.02$ & $0.30 \pm 0.02$ \\
\hline 10.69 & 3-methyl-phenol & 108 & $0.50 \pm 0.02$ & $0.60 \pm 0.02$ & - & $0.70 \pm 0.03$ \\
\hline 11.31 & 4-methyl-phenol & 108 & $1.00 \pm 0.04$ & $0.50 \pm 0.02$ & $0.40 \pm 0.02$ & $0.70 \pm 0.03$ \\
\hline 11.66 & Guaiacol & 124 & $0.30 \pm 0.02$ & $0.50 \pm 0.02$ & - & $0.40 \pm 0.02$ \\
\hline 11.77 & Unknown & 126 & $0.30 \pm 0.02$ & $1.00 \pm 0.04$ & $1.40 \pm 0.10$ & $1.70 \pm 0.10$ \\
\hline 12.52 & $\begin{array}{l}\text { 3-ethyl-2-hydroxy-2-cyclopenten-1- } \\
\text { one }\end{array}$ & 126 & $0.50 \pm 0.02$ & $0.60 \pm 0.02$ & $0.50 \pm 0.02$ & $0.80 \pm 0.03$ \\
\hline 13.29 & $\begin{array}{l}\text { 3,5-dihydroxy-6-methyl-2,3-dihydro- } \\
\text { 4H-pyran-4-one }\end{array}$ & 144 & $0.50 \pm 0.02$ & $0.10 \pm 0.01$ & $0.10 \pm 0.01$ & $0.10 \pm 0.01$ \\
\hline 13.41 & Dimethyl phenol & 122 & $0.40 \pm 0.02$ & $0.30 \pm 0.02$ & $0.30 \pm 0.02$ & $0.50 \pm 0.02$ \\
\hline 13.88 & Unknown & 138 & - & - & $0.6 \pm 0.02$ & - \\
\hline 13.95 & 4-ethyl-phenol & 122 & $0.70 \pm 0.03$ & $0.6 \pm 0.03$ & - & $0.40 \pm 0.02$ \\
\hline 14.50 & 3,5-dihydroxy-2-methyl-4-pyrone & 142 & $0.40 \pm 0.02$ & - & - & - \\
\hline 14.65 & $\mathrm{C}_{10} \mathrm{H}_{20} \mathrm{O}$ monoterpenoid & 138 & $0.40 \pm 0.02$ & $0.70 \pm 0.03$ & $0.50 \pm 0.02$ & - \\
\hline 15.08 & Unknown & 140 & $0.2 \pm 0.02$ & $0.6 \pm 0.03$ & $0.40 \pm 0.02$ & - \\
\hline 15.17 & Unknown & 144 & - & - & - & $1.20 \pm 0.05$ \\
\hline 15.41 & 4-vinylphenol & 120 & $0.40 \pm 0.02$ & $1.40 \pm 0.10$ & $1.10 \pm 0.05$ & $0.20 \pm 0.02$ \\
\hline 15.76 & 5-Hydroxymethyl-2-furaldehyde & 126 & $0.50 \pm 0.02$ & $0.60 \pm 0.03$ & - & - \\
\hline 17.06 & Ethyl guaiacol & 152 & $0.30 \pm 0.02$ & $0.40 \pm 0.02$ & $0.20 \pm 0.01$ & $0.30 \pm 0.02$ \\
\hline 17.48 & $\mathrm{C}_{8} \mathrm{H}_{7} \mathrm{~N}$ & 117 & $0.70 \pm 0.03$ & $0.10 \pm 0.01$ & $0.20 \pm 0.01$ & $0.30 \pm 0.02$ \\
\hline 18.01 & 4-vinylguaiacol & 150 & $0.80 \pm 0.03$ & $1.20 \pm 0.05$ & $1.10 \pm 0.05$ & $1.00 \pm 0.05$ \\
\hline 19.00 & Syringol & 154 & $0.20 \pm 0.01$ & $0.70 \pm 0.03$ & $0.50 \pm 0.02$ & $0.20 \pm 0.01$ \\
\hline 19.17 & Eugenol & 164 & - & $0.10 \pm 0.01$ & - & - \\
\hline 19.94 & $\mathrm{C}_{9} \mathrm{H}_{9} \mathrm{~N}$ 5-methyl-indole & 131 & $0.10 \pm 0.01$ & - & - & $0.20 \pm 0.02$ \\
\hline 20.44 & Vanillin & 152 & $0.30 \pm 0.02$ & - & - & - \\
\hline 20.48 & Cis-isoeugenol & 164 & - & $0.10 \pm 0.01$ & - & $0.10 \pm 0.01$ \\
\hline 20.71 & Trans-isoeugenol & 164 & $0.10 \pm 0.01$ & $0.10 \pm 0.01$ & - & - \\
\hline 21.52 & Eugenol & 164 & - & $0.40 \pm 0.02$ & $0.10 \pm 0.01$ & $0.10 \pm 0.01$ \\
\hline $22.27-22.33$ & 1,6-anhydro-hexose & 162 & $0.20 \pm 0.02$ & $0.60 \pm 0.02$ & $0.80 \pm 0.03$ & - \\
\hline 22.70 & $\mathrm{C}_{10} \mathrm{H}_{10} \mathrm{O}_{2}$ & 162 & $0.20 \pm 0.02$ & - & - & $0.50 \pm 0.02$ \\
\hline 24.31 & 4-vinyl syringol & 180 & - & $0.40 \pm 0.02$ & $0.30 \pm 0.02$ & \\
\hline 27.39 & 4-allyl syringol & 194 & - & $0.30 \pm 0.02$ & $0.10 \pm 0.01$ & $0.10 \pm 0.01$ \\
\hline 28.19 & Coniferyl alcohol & 180 & - & $0.50 \pm 0.02$ & - & - \\
\hline 28.60 & Myristic acid & 228 & $0.10 \pm 0.01$ & $0.10 \pm 0.01$ & $0.10 \pm 0.01$ & $0.10 \pm 0.01$ \\
\hline 32.70 & Palmitic acid & 256 & $1.60 \pm 0.10$ & $1.30 \pm 0.05$ & $1.50 \pm 0.10$ & $1.90 \pm 0.10$ \\
\hline 34.92 & Octadecanol & 270 & - & $0.20 \pm 0.01$ & - & - \\
\hline 35.85 & linoleic acid & 280 & $0.30 \pm 0.02$ & - & $0.10 \pm 0.01$ & $0.50 \pm 0.02$ \\
\hline 35.97 & Octadecadienoic acid & 280 & $0.40 \pm 0.02$ & $0.30 \pm 0.02$ & $0.30 \pm 0.02$ & $0.70 \pm 0.03$ \\
\hline 36.34 & Stearic acid & 284 & $0.20 \pm 0.01$ & $0.20 \pm 0.01$ & $0.20 \pm 0.01$ & $0.20 \pm 0.01$ \\
\hline 49.89 & $\begin{array}{l}\text { 4,14-dimethyl-9,19-cycloergost-24(28)- } \\
\text { en-3-ol acetate isomer }\end{array}$ & 468 & $0.60 \pm 0.02$ & - & $0.20 \pm 0.01$ & $1.20 \pm 0.05$ \\
\hline 50.03 & $\begin{array}{l}\text { 4,14-dimethyl-9,19-cycloergost-24(28)- } \\
\text { en-3-ol acetate isomer }\end{array}$ & 468 & $1.60 \pm 0.10$ & - & $0.20 \pm 0.01$ & $1.50 \pm 0.10$ \\
\hline 50.17 & $\begin{array}{l}\text { 9,19-cyclo-9a-lanost-24-en-3a-ol } \\
\text { acetate }\end{array}$ & 468 & $0.30 \pm 0.02$ & $0.20 \pm 0.01$ & $0.40 \pm 0.02$ & $0.70 \pm 0.03$ \\
\hline 50.74 & Unknown steroid & 430 & $1.00 \pm 0.04$ & $0.10 \pm 0.01$ & $0.30 \pm 0.02$ & $1.60 \pm 0.10$ \\
\hline
\end{tabular}


TABLE 6. Continued

\begin{tabular}{lllrrrr}
$\begin{array}{l}\text { Retention } \\
\text { time (min) }\end{array}$ & \multicolumn{1}{c}{\begin{tabular}{c} 
Compound \\
\cline { 5 - 7 }
\end{tabular}} & \multicolumn{1}{c}{$\begin{array}{c}\text { BP } \\
\text { \% area peak }\end{array}$} & BPS & BR & PP \\
\hline 50.88 & Unknown steroid & 408 & $1.80 \pm 0.10$ & - & $0.10 \pm 0.01$ & $1.50 \pm 0.10$ \\
52.00 & Unknown steroid & 400 & $0.30 \pm 0.02$ & $0.20 \pm 0.01$ & $0.40 \pm 0.02$ & $0.20 \pm 0.01$ \\
52.34 & Stigmasterol & 412 & $0.50 \pm 0.02$ & $0.30 \pm 0.02$ & $0.60 \pm 0.02$ & $0.20 \pm 0.01$ \\
53.10 & Sitosterol & 414 & $0.60 \pm 0.02$ & $0.30 \pm 0.02$ & $0.60 \pm 0.02$ & $0.20 \pm 0.01$ \\
53.90 & Unknown steroid & 424 & $2.80 \pm 0.10$ & - & $0.70 \pm 0.03$ & $5.60 \pm 0.20$ \\
54.15 & Unknown steroid & 424 & $10.90 \pm 0.40$ & - & $0.50 \pm 0.02$ & $6.30 \pm 0.30$ \\
54.50 & Unknown steroid & 424 & $0.60 \pm 0.02$ & - & - & $0.40 \pm 0.02$ \\
\hline
\end{tabular}

\section{Analytical Pyrolysis Gas Chromatography and Mass Spectrometry (Py-GC/MS)}

During biomass pyrolytic processes, diverse organic species are generated from the thermal breakdown of the polymeric constituents of biomass. Analytical Py-GC/MS technique has demonstrated potential for determining the organic species formed during thermochemical conversion.

Table 6 lists the compounds detected during analytical pyrolysis at $500^{\circ} \mathrm{C}$. More than 60 chemical components were detected and about three-quarter of the compounds were identified (Table 6). It was observed that furan, acetic acid and 1-hyddroxy-2-propanone were among the earliest chemical species liberated from the four biomass resources investigated and BPS had the highest quantity of each: 8.0, 9.5, and 8.4 , respectively. The ratio of the phenolic compounds identified was more than half; however, the main ones were phenol, methyl-phenols, guaiacyl derivatives, and syringyl derivatives. These have emerged from the cleavage of some linkages in the lignin fractions. This trend is in consonance with findings from literature $[16,20]$. It is noteworthy that limonene, in significant amount, was detected only in the peels. This may be associated with some differences in the morphological makeup of the biomass resources being studied. A range of sterols was also detected and this is consistent with the findings by Oliveira et al. on detailed analysis of banana residue extracts [6]. The concentration of sterols found in the peels was notably higher than those in the other morphological parts being studied (pseudo-stem and rachis). This trend agrees with literature, in which free sterols were found to be more abundant in banana peels in comparison to its pulp [6]. The number of unsaturated fatty acids (only linoleic) detected was less than that of the saturated fatty acids; a trend that conforms to findings in literature [6]. Significantly, the following saturated fatty acids: myristic, palmitic, octadecadienoic, stearic acids were identified in all the biomass samples investigated. This reinforces the earlier assertion that Musa spp. residues are potential sources of valorization both in the nutraceutical and biochemical industries.

\section{CONCLUSION}

Different tissues from Musa spp. residues were successfully characterized and marked distinctions existed in the experimental data as a function of different morphological parts. The presence of starch, with a starch crystallinity ranging from 0.9 and 1.0, was confirmed in the peels. On the other hand, the cellulose crystallinity index $(\approx 0.6)$ confirmed the presence cellulose I in both the pseudo-stem and rachis samples.

The TGA revealed the biomass thermal decomposition behaviour from which the decomposition mechanism of the lignocellulosic fractions was inferred. A consistency in the kinetic data was noted as the average values of the $E_{\mathrm{a}}$ obtained for the integral and differential methods differed by less than 3\%. However, the kinetic data showed the complex nature of the activation energy dependence on conversion; thus biomass decomposition kinetics can be better interpreted as a multistep reaction mechanism. The lignin degradation products made up more than half of the chemical species identified.

\section{ACKNOWLEDGMENTS}

The authors would like to acknowledge Noureddine Anibou at Rigaku America Corporation in acquiring the XRD data.

\section{LITERATURE CITED}

1. Adeoye, I.B., Oni, O.A., Yusuf, S.A., \& Adenegan, K.O. (2013). Plantain value chain mapping in Southwestern Nigeria, Journal of Economics and Sustainable Development, 4, 137-145.

2. Morris, K.J.K., \& Kamarulzaman, N.H. (2014). Conceptual framework for estimating postharvest losses in food supply chains: The case of plantains fruits in Nigeria, International Journal of Business Economic Research, 3, 3137.

3. Food and Agriculture Organization of the United Nations (FAOSTAT 2017). http://www.fao.org/faostat/en/ \#data/QC/visualize

4. Amoo-Gottfried, K., \& Hall, D.O. (1999). A biomass energy flowchart for Sierra Leone, Biomass and Bioenergy, 16, 361-376.

5. Cordeiro, N., Belgacem, M.N., Torres, I.C., \& Moura, J.V.C.P. (2004). Chemical composition and pulping of banana pseudo-stems, Industrial Crops and Products, 19, $147-154$

6. Oliveira, L., Freire, C.S.R., Silvestre, A.J.D., \& Cordeiro, N. (2008). Lipophilic extracts from banana fruit residues: A source of valuable phytosterols, Journal of Agricultural Food Chemistry, 56, 9520-9524.

7. Oliveira, L., Cordeiro, N., Evtuguin, D.V., Torres, I.C., \& Silvestre, A.J.D. (2007). Chemical composition of different morphological parts from 'Dwarf Cavendish' banana plant and their potential as a non-wood renewable source of natural products, Industrial Crops and Products, 26, 163-172.

8. Guimarães, J.L., Frollini, E., da Silva, C.G., Wypych, F., \& Satyanarayana, K.G. (2009). Characterization of banana, sugarcane bagasse and sponge gourd fibers of Brazil, Industrial Crops and Products, 30, 407-415.

9. Rindlav, A., Hulleman, S.H.D., \& Gatenholm, P. (1997). Formation of starch films with varying crystallinity, Carbohydrate Polymers, 34, 25-30.

10. Lopez-Rubio, A., Flanagan, B.M., Gilbert, E.P., \& Gidley, M.J. (2008). A novel approach for calculating starch crystallinity and its correlation with double helix content: A combined XRD and NMR study, Biopolymers, 89, 761768.

11. Wei, L., McDonald, A.G., \& Stark, N.M. (2015). Grafting of bacterial polyhydroxybutyrate (PHB) onto cellulose via 
in-situ reactive extrusion with dicumyl peroxide, Biomacromolecules, 16, 1040-1049.

12. Lopez-Velazquez, M.A., Santes, V., Balmaseda, J., \& Torres-Garcia, E. (2013). Pyrolysis of orange waste: A thermo-kinetic study, Journal of Analytical and Applied Pyrolsis, 99, 170-177.

13. Burhenne, L., Messmer, J., Aicher, T., \& Laborie, M. (2013). The effect of the biomass components lignin, cellulose and hemicellulose on TGA and fixed bed pyrolysis, Journal of Analytical and Applied Pyrolsis, 101, 177184.

14. Gai, C., Dong, Y., \& Zhang, T. (2013). The kinetic analysis of the pyrolysis of agricultural residue under nonisothermal conditions, Bioresource Technology, 127, 298305.

15. Gao, N., Li, A., Quan, C., Du, L., \& Duan, Y. (2013). TGFTIR and Py-GC/MS analysis on pyrolysis and combustion of pine sawdust, Journal of Analytical and Applied Pyrolsis, 100, 26-32.

16. Balogun, A.O., Lasode, O.A., \& McDonald, A.G. (2014). Devolatilisation kinetics and pyrolytic analyses of Tectona grandis (teak), Bioresource Technology, 156, 57-62.

17. Iiyama, K., \& Wallis, A.F.A. (1988). An improved acetyl bromide procedure for determining lignin in wood and wood pulps, Wood Science and Technology, 22, 271280.

18. Green, T.R., \& Popa, R. (2010). A simple assay for monitoring cellulose in paper-spiked soil, Journal of Polymer \& Environment, 18, 634-637.

19. Balogun, A.O., Lasode, O.A., Hui, L., \& McDonald, A.G. (2015). Fourier Transform Infrared (FTIR) study and thermal decomposition kinetics of Sorghum bicolour glume and Albizia pedicellaris residues, Waste and Biomass Valorization, 6, 109-116.

20. Balogun, A.O., \& McDonald, A.G. (2016). Decomposition kinetic study, spectroscopic and pyrolytic analyses of Isoberlinia doka and Pinus Ponderosa, Biomass Conversion and Biorefinery, 6, 315-324.

21. Osman, N.B., McDonald, A.G., \& Laborie, M.G. (2012). Analysis of DCM extractable components from hotpressed hybrid poplar, Holzforschung, 66, 927-934.

22. Slopiecka, K., Bartocci, P., \& Fantozzi, F. (2012). Thermogravimetric and kinetic study of poplar wood pyrolysis, Applied Energy, 97, 491-497.

23. Kamsonlian, S., Suresh, S., Majumder, C.B., \& Chand, S. (2011). Characterization of banana and orange peels: Biosorption mechanism, International Journal of Science Technology and Management, 2, 1-7.

24. Miles, T.R., Miles, J.T.R., Baxter, L.L., Bryers, R.W., Jenkins, B.M., \& Oden, L.L. (1995). Alkali deposits found in biomass power plants. A preliminary investigation of their extent and nature, Report of the National Renewable Energy Laboratory (NREL/TZ-2-11226-1; TP-4338142).

25. Vassilev, S.V., Baxter, D., Andersen, L.K., \& Vassileva, C.G. (2010). An overview of the chemical composition of biomass, Fuel, 89, 913-933.

26. Balogun, A.O., Lasode, O.A., \& McDonald, A.G. (2014). Thermo-analytical and physico-chemical characterization of woody and non-woody biomass from an agroecological zone in Nigeria, Bioresources, 9, 5099-5113.

27. Abdullah, N., Sulaiman, F., Miskam, M.A., \& Taib, R.M. (2014). Characterization of banana (Musa spp.) pseudostem and fruit-bunch-stem as a potential renewable energy resource, International Journal of Biological,
Biomolecular, Agricultural, Food, and Biotechnological Engineering, 8, 815-819.

28. Jeyasingam, J.T. (1988). A summary of special problems and considerations related to non wood pulping worldwide. In TAPPI Pulping Conference (Volume III), New Orleans, LA.

29. Keitaanniemi, O., \& Virkola, N.-E. (1982). Undesirable elements in causticizing systems, TAPPI, 65, 89-92.

30. Obernberger, I., Biederman, F., Widman, W., \& Riedl, R. (1997). Concentrations of inorganic elements in biomass fuels and recovery in the different ash fractions, Biomass and Bioenergy, 12, 211-224.

31. Ilvessalo-Pfäffli, M.-S. (1995). Fiber atlas. Identification of papermaking fibers. Berlin: Springer.

32. Liang, S., Gliniewicz, K., Gerritsen, A.T., \& McDonald, A.G. (2016). Analysis of microbial community variation during the mixed culture fermentation of agricultural peel wastes to produce lactic acid, Bioresource Technology, 208, 7-12.

33. Telmo, C., \& Lousada, J. (2011). The explained variation by lignin and extractives contents on higher heating value of wood, Biomass and Bioenergy, 35, 1663-1667.

34. Soria, J.A., McDonald, A.G. (2012). Liquefaction of softwoods and hardwoods in supercritical methanol: A novel approach to bio-oil production. In C. Baskar, S. Baskar, R.S. Dhillon (Eds.), Biomass conversion: The interface of biotechnology, chemistry and materials science (pp. 421433), Berlin: Springer.

35. Akerholm, M., Hinterstoisser, B., \& Salmen, L. (2004). Characterization of the crystalline structure of cellulose using static and dynamic FT-IR spectroscopy, Carbohydrate Research, 339, 569-578.

36. Oliveira, L., Evtuguin, D., Cordeiro, N., \& Silvestre, A.J.D. (2009). Structural characterization of stalk lignin from banana plant, Industrial Crops Products, 29, 86-95.

37. Van Soest, J.J.G., Tournois, H., de Wit, D., \& Vliegenthart, J.F.G. (1995). Short-range structure in (partially) crystalline potato starch determined with attenuated total reflectance Fourier-transform IR spectroscopy, Carbohydrate Research, 279, 201-214.

38. Velasquez-Cock, J., Castro, C., Ganan, P., Osorio, M., Putaux, P.L., Serpa, A., \& Zuluaga, R. (2016). Influence of the maturation time on the physico-chemical properties of nanocellulose and associated constituents isolated from pseudostems of banana plant c.v. Valery, Industrial Crops Products, 83, 551-560.

39. Nagy, M., Kerr, B.J., Ziemer, C.J., \& Ragauskas, A.J. (2009). Phosphitylation and quantitative 31P NMR analysis of partially substituted biodiesel glycerols, Fuel, 88, 1793-1897.

40. Xiang, T., Amin, R.A.M. (2011). Water-based mud lubricant using fatty acid polyamine salts and fatty acid esters, United States patent US 20110036579.

41. Gaur, S., Reed, T.B. (1998). Thermal data for natural synthetic fuels. New York, NY: Marcel Dekker.

42. Oladokun, O., Ahmad, A., Abdullah, T.A.T., Nyakuma, B.B., Bello, A.A.-H., \& Al-Shatri, A.H. (2016). Multicomponent devolatilization kinetics and thermal conversion of Imperata Cylindrica, Applied Thermal Engineering, 105, 931-940.

43. Lasode, O.A., Balogun, A.O., \& McDonald, A.G. (2014). Torrefaction of some Nigerian lignocellulosic resources and decomposition kinetics, Journal of Analytical Applied Pyrolosis, 109, 47-55. 